\title{
RALF: an adaptive reinforcement learning framework for teaching dyslexic students
}

\author{
Seyyed Amir Hadi Minoofam ${ }^{1} \cdot$ Azam Bastanfard $^{1} \cdot$ Mohammad Reza Keyvanpour $^{2}$
}

Received: 12 July 2021 / Revised: 9 September 2021 / Accepted: 14 December 2021 /

Published online: 10 January 2022

(c) The Author(s), under exclusive licence to Springer Science+Business Media, LLC, part of Springer Nature 2022

\begin{abstract}
Dyslexia is a learning disorder in which individuals have significant reading difficulties. Previous studies found that using machine learning techniques in content supplements is vital in adapting the course concepts to the learners' educational level. However, to the best of our knowledge, no research objectively applied machine learning methods to adaptive content generation. This study introduces an adaptive reinforcement learning framework known as RALF through Cellular Learning Automata (CLA) to generate content automatically for students with dyslexia. At first, RALF generates online alphabet models as a simplified font. CLA structure learns each rule of character generation through the reinforcement learning cycle asynchronously. Second, Persian words are generated algorithmically. This process also considers each character's state to decide the alphabet cursiveness and the cells' response to the environment. Finally, RALF can generate long texts and sentences using the embedded word-formation algorithm. The spaces between words are proceeds through the CLA neighboring states. Besides, RALF provides word pronunciation and several exams and games to improve the learning performance of people with dyslexia. The proposed reinforcement learning tool enhances students' learning rate with dyslexia by almost $27 \%$ compared to the face-to-face approach. The findings of this research show the applicability of this approach in dyslexia treatment during Lockdown of COVID-19.
\end{abstract}

Keywords Educational multimedia $\cdot$ Integrated communication $\cdot$ Intelligent tutoring system $\cdot$ Orthographic knowledge $\cdot$ Pandemic crisis

Azam Bastanfard

bastanfard@kiau.ac.ir

Seyyed Amir Hadi Minoofam minoofam@qiau.ac.ir

Mohammad Reza Keyvanpour

keyvanpour@alzahra.ac.ir

1 Department of Computer Engineering, Karaj Branch, Islamic Azad University, Karaj, Iran

2 Department of Computer Engineering, Faculty of Engineering, Alzahra University, Tehran, Iran 


\section{Introduction}

Computer-assisted language learning (CALL) is a powerful tool for distance learning or is a teaching assistant to help the learners [71, 73]. E-learning is referred to as an ongoing trend in the research world [37, 89]. Also, various computer graphics techniques play essential roles in any educational system [19, 68]. Furthermore, machine learning approaches [67] provide a convenient way to computer-assisted systems such as Fuzzy rule-based [20, 55], prediction [27, 34], clustering [77, 78], video-based human interaction [41, 42], motion recognition [29, 40], and human-computer cooperation [58, 59]. For example, students could access the academic papers through the digital libraries, debate their projects with their consultants through e-mail, and attend web-based courses at home $[6,90]$. Thus, web technology facilitates learning, especially in schools [43]. By expanding the Internet and social networks, the education procedure is restructured, and the tutoring software is developed more and more [38, 70].

Dyslexia is a difficulty in learning that addresses some disorders in word recognition, spelling, and phonic skills besides remembering short-term memory instructions $[22,49]$. About $10 \%$ of people suffer from dyslexia disorder, and there is much research on their identification and support [31, 33]. One of the most communicative areas in education during COVID-19 is orthography learning appended in educational software if it has an algorithmic approach [88].

Dyslexia disorder in children is a two-fold problem motivating the topic of this study. On the one hand, dyslexia is an intellectual impairment, and people with dyslexia barely could explain their situation to others [84]. On the other hand, dealing with children, training them, and getting their feedback could be troublesome [10]. This research aims to generate Persian scripts in a simple font for students with dyslexia disorder. The choice for the type of glyphs and fonts plays a significant role in the complexity of the alphabets [17]. The purpose of glyphs could be helpful in psychological studies, too [92]. Unfortunately, little research has considered font styles in students' reading skills with dyslexia [66] [72].

In this study, a new modeling algorithm for dyslexia treatment is introduced. Reinforcement learning is a branch of machine learning in which the reward and penalty strategy is used [60]. We consider a reinforcement learning approach [18], namely, Cellular Learning Automata (CLA), as the learning method [56, 95]. CLA also has the capability of procedural modeling because it originates from Cellular Automata (CA) [79, 97]. The main advantage of reinforcement learning methods is that they do not require any training data at all. In contrast, they learn from the environment and gradually improve their action until they converge to optimal. Up to now, CLA has been used as a tool to train the machine [13, 50]. Unfortunately, to the best of our knowledge, no research applied machine learning approaches to generate compelling content for humans' learning, especially for students with dyslexia. Surprisingly, in the current study, CLA is adapted to emulate the learning of the human mind. In other words, CLA could follow the learning procedure in the brain of any humankind. Therefore, utilizing CLA in a pictorial context provides a novel method regarding educational psychology. Since the CLA operation is according to the reward/ penalty system, it conducts the mind to correct reading patterns concepts as a remedy for dyslexia.

The main contributions of RALF as an Adaptive Reinforcement Learning Framework for Dyslexics are as follows:

- Teach the reading capability of the Persian language through an audio-visual process. 
- Text generation without common drawbacks of CALL systems such as character and word restrictions

- Online machine learning approach to adaptive content generation for learners

- The step-by-step representation of the writing process of any letters by a virtual pen that guides the eye movement of students with dyslexia

First, it teaches the Persian language's reading capability utilizing CLA as a reinforcement modeling tool to generate texts without usual CALLs such as characters or words limitation. Secondly, it represents the process of text generation step by step with a virtual pen that guides the eye movement of dyslexic students. Third, the pronunciation of each word is played during its graphical formation process. Forth, the proposed system represents learning games to practice the Persian training words. Finally, RALF provides a graphics-based exam to assess the progress of dyslexic learners.

The remaining sections of the paper are organized as follows. Section 2 provides a literature review of CALLs for dyslexic students. Section 3 considers the background concepts, and Sect. 4 describes the proposed RALF system as a reinforcement modeling tool. In Sect. 5, the results and evaluation of the proposed approach are considered. Section 6 describes the discussion of RALF training through dyslexic students and its challenges. Finally, Sect. 7 concludes the paper with some remarks about future work.

\section{Literature review}

The related works that are discussed in this section are based on the in-depth investigation of published research in the last five years regarding the use of computer applications for dyslexia. The educational systems for the students with dyslexia are related to two folds of the research area. On the one hand, the script synthesis process should be analyzed [52]. Cellular automata have been used for script generation successfully [51]; however, the letter design did not cover all default letters. Furthermore, production rules play a vital role in script synthesis [23], but their generation process is complicated.

On the other hand, the handwritten recognition process demonstrates writing features in an analytical method [45, 47]. Manuscript recognition empowers the ability of character and number consideration of handwriting [46]. Handwritten recognition has developed advanced algorithms in different languages such as Gurumukhi [48], Devanagari [63], Urdu [62], and Persian [39, 57]. In addition, some recent research assesses the children's handwriting in different languages such as English [81, 96], kanji [65], and Chinese [94]. At the same time, they did not provide a procedure to improve their handwriting by graphical education. The data in Table 1 summarizes the features of CALL systems in previous studies. Besides the diversity in approaches in using machine learning methods, various evaluations are used to assess the CALL systems in the literature. Furthermore, the 2D or 3D dimension and graphical generation of alphabets is compared among previous studies.

According to the analysis of previous studies, several research areas are neglected by recent works. The advantages of the proposed RALF system to fill the research gap of the earlier studies are as follows. First, it provides an interactive tool to generate all letters automatically. Second, the generation process is simple by using reinforcement learning. Third, the letter-writing process is represented through computer graphics to educate the learners via their eyes. Forth, the graphical generation is combined with their pronunciation sound. 
Table 1 A brief review of computer applications for dyslexia

\begin{tabular}{llllll}
\hline Reference & Machine learning & age & Feature & Graphical generation & Eval. metrics \\
\hline$[5]$ & - & School student & 2D & - & ANCOVA \\
{$[44]$} & - & University student & 2D & - & GLM \\
{$[85]$} & Agent & School student & 3D & Pseudo shapes & Interview \\
{$[36]$} & SVM-PSO & School student & 2D & - & Classification criteria \\
{$[72]$} & - & General group & 2D & - & $\chi 2$ test \\
{$[15]$} & - & General group & 2D & - & Feature comparison \\
{$[3]$} & - & School student & 2D & - & T-test \\
{$[16]$} & - & School student & 2D & - & T-test \\
\hline
\end{tabular}

Finally, all aspects of RALF are organized using a simple font to make alphabet learning easy for students with dyslexia.

\section{Background}

In this section, two major background concepts are considered. The first preliminary item is the simplified font used in RALF, the Persian characters' list, and their characteristics. The Persian characters' attributes play a significant role in the alphabet generation in reinforcement learning algorithms. The second concept is the cellular learning automata (CLA), which is used to generate Persian characters in this study.

\subsection{Simplified Persian script}

In this study, an ancient simplified font known as Square Kufic is used for script generation to facilitate reading for students with dyslexia. Historical research reveals that the Square Kufic [1] or Ma'qeli [100] script is among the preliminary media for human interaction [8]. Primitive communities used painted scripts for communication between each other and left their imagination for future people. Nowadays, script and its branches like handwriting and typography inevitably play a vital role in creating a link between individuals and communications [26]. The rationale behind the script as a medium for interaction lies in five different critical features as i) simplicity, ii) appeal, iii) readability, iv) flexibility, and v) scalability. The simplicity feature provides an appropriate platform for the widespread use of the script and maybe leveraged to design an algorithmic procedure to generate the script. The script's readability is a powerful feature for human readers and is a facility attribute for recognition [21]. The appealing property draws the attention of the viewer to the written text. Notably, the historic and mysterious fonts attract people to analyze the words' appearance and meaning [76]. The flexible nature determines the glyphs' reshaping property, suitable for typography and writing in geometrical designs. The script's last but not pivotal characteristic is its scalability for other contexts or languages [2]. One of the popular scripts with all the five key features is the Ma'qeli script, also known as square Kufic or Bannaei [100]. The Ma'qeli script affected the stakeholder when reading the words, as in Fig. 1.

Persian language (Farsi) is written like the Arabic script with a few differences. There

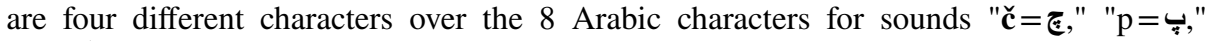

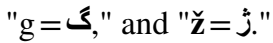




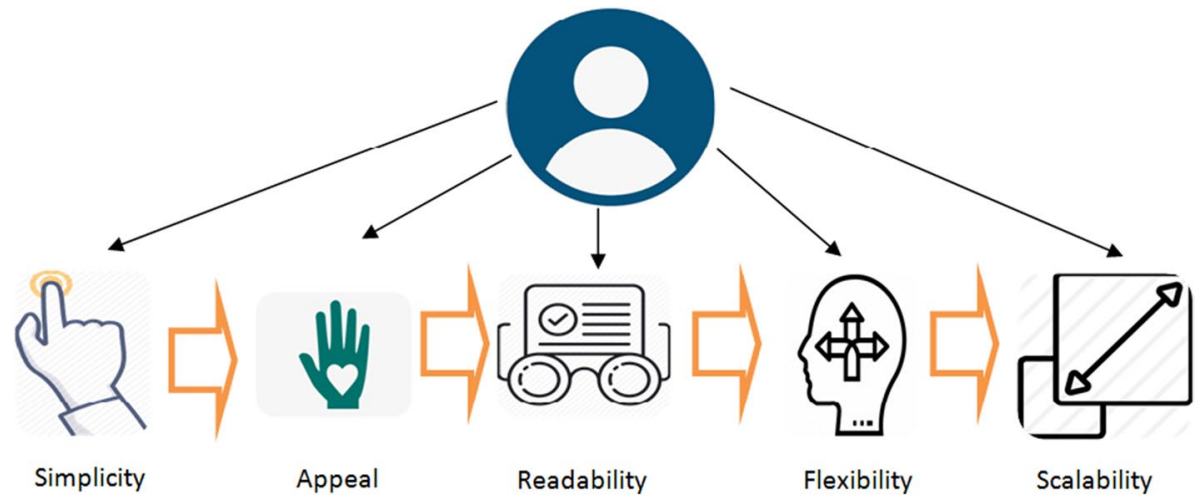

Fig. 1 Stakeholder engagement of Ma'qeli script

In the English language, the form of characters depends on their global position and is one of the two cases: lower and UPPER. Similarly, in the Persian language, the form of characters depends upon their position in the word. There are four cases due to the letters' cursiveness: Initial, Medial, Final, and Isolated. The Persian alphabet showing all four forms is illustrated in Table 2. It seems there is a need for a straightforward approach in teaching the students via applying an easy-understanding script. A special kind of ancient script known as Ma'qeli in Persian/Arabic could solve this challenging area. The Ma'qeli script consists of only straight lines with no curvatures. This paper considers the underlying rules and the features of the Ma'qeli script that provide flexibility to represent different words. Furthermore, the mappings of Ma'qeli script in other languages such as English with their capability in legibility by individuals and machines are emphasized.

Table 2 The Persian alphabet

\begin{tabular}{|c|c|c|c|c|c|c|c|c|c|}
\hline Name & Initial & Medial & Final & Isolated & Name & Initial & Medial & Final & Isolated \\
\hline$\overline{\mathrm{a}}[\mathrm{p}]$ & $i / l$ & -1 & -1 & $i / l$ & ș [s] & ص - & -ص- & ص- & ص \\
\hline $\mathrm{b}[\mathrm{b}]$ & -ب & ب- & ب- & ب & $\mathrm{z}[\mathrm{z}]$ & ض & ض- & ض- & ض \\
\hline $\mathrm{p}[\mathrm{p}]$ & 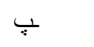 & بי & بـ- & 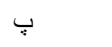 & $t[t]$ & b & b & h & $b$ \\
\hline$t[t]$ & ت & تــ & تـ & ت & $\mathrm{z}[\mathrm{z}]$ & ظ & 亡 & ظـ & ظ \\
\hline$\underline{\mathrm{s}}[\mathrm{s}]$ & ث & - ث- & ث- & $ث$ & ' [?] & $\varepsilon-$ & $-\varepsilon-$ & $-\varepsilon$ & $\varepsilon$ \\
\hline $\mathrm{j}\left[\bar{d}_{3}\right]$ & - & -ج- & ج- & ج & $\dot{\mathrm{g}}[\mathrm{\gamma}]$ & $\dot{\varepsilon}-$ & $\dot{-\varepsilon}$ & $-\dot{\varepsilon}$ & $\dot{\varepsilon}$ \\
\hline$\check{c}$ [tJ] & ج- & - ש- & שَ- & ङ & $f[f]$ & - & -ف- & ف- & ف \\
\hline $\mathrm{h}[\mathrm{h}]$ & $\tau^{-}$ & $\tau^{-}$ & $\tau$ & $\tau$ & $\mathrm{q}[\mathrm{q}]$ & ق & قق & ق- & ق \\
\hline$x[\mathrm{x}]$ & $\dot{\tau}^{-}$ & $\dot{\tau}^{-}$ & $-\dot{\tau}$ & $\dot{\tau}$ & $\mathrm{k}[\mathrm{k}]$ & ك & كــ & كــ & s \\
\hline $\mathrm{d}[\mathrm{d}]$ & 2 & -2 & د) & 2 & $\mathrm{~g}[\mathrm{~g}]$ & ב & عــ & كــ & 3 \\
\hline$\underline{\mathrm{z}}[\mathrm{z}]$ & ذ & ذـ. & ذـ & ذ & $1[1]$ & $\mathcal{J}$ & - & J & J \\
\hline $\mathrm{r}[\mathrm{r}]$ & נ & נ- & נ- & נ & $\mathrm{m}[\mathrm{m}]$ & 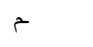 & ז- & 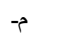 & b \\
\hline $\mathrm{z}[\mathrm{z}]$ & j & ز- & j- & j & $\mathrm{n}[\mathrm{n}]$ & - & -ن- & ن- & ن \\
\hline$\check{z}$ [3] & $j$ & j & j- & j & $\mathrm{v}[\mathrm{v}]$ & g & -9 & -9 & 9 \\
\hline $\mathrm{s}[\mathrm{s}]$ & س س & س- & س- & س & $\mathrm{h}[\mathrm{h}]$ & 0 & $-\infty$ & - & 。 \\
\hline$\check{s}\left[\int\right]$ & ش & ش- & ش- & ش ش & $\mathrm{y}[\mathrm{p}:]$ & - & - - - & ى- & $\checkmark$ \\
\hline
\end{tabular}




\subsection{Cellular learning automata}

This subsection consists of an introduction to the cellular learning automata concept and its related topics. Because of CLA's hybrid nature, it is worth first looking at its building blocks, i.e., learning automata and cellular automata.

- Learning Automata

Learning Automata (LA) is an adaptive decision-making machine with some actions for evaluating the environment [53]. Results of this evaluation return as a feedback loop to the automata as a reward or penalty signal. At the next iteration, the automata choose the following action based on the receiving response from the environment. The final aim is to select the best action by the automata, which has the lowest probability of being penalized [64].

- Cellular Automata

Cellular Automata (CA) is a computing model that performs complicated tasks through local interaction between cells. Generally, CA is a grid of cells that can impact each other through a transition rule. The transition rule is often defined as a relation between the state of the current cell and the states of its neighbor cells [93].

\section{- Cellular Learning Automata}

A cellular learning automaton is a cellular automaton with some learning automata[91] in each cell. The CLA is formally defined as Definition $1[11,50]$.

Definition1. Cellular learning automaton is a five-tuple $<\mathrm{Z}^{\mathrm{d}}, \Phi, \mathrm{A}, \mathrm{N}, \mathrm{F}>$ where

- $\mathrm{Z}^{\mathrm{d}}$ : a lattice with d tuples of integer numbers

- $\Phi$ : a finite set of cell states

- A: set of LAs for each cell

- $\quad \mathrm{N}$ : neighbor vector, a subset of $\mathrm{Z}^{\mathrm{d}}$

- $F: \Phi^{\mathrm{m}} \rightarrow \beta$ function for computing the response of the environment

The CLA iteratively operates as follows:

Step 1: Each of the LAs in $\mathrm{Z}^{\mathrm{d}}$ such as $A_{i} \in A$ chooses an action $\alpha_{i}$ which takes $A_{i}$ to a new state $\varphi_{i} \in \Phi$ and applied the action to the environment.

Step 2: The environment sends a reinforcement signal to all $A_{i} \in A$ based on the function $F: \Phi^{\mathrm{m}} \rightarrow \beta$.

Step 3: Each LA $A_{i} \in A$ takes a new state $\varphi_{i+1}$ according to its previous state $\varphi_{i}$ and the new state of their neighbors $n_{i} \in N$.

According to their operation, cellular learning automata are divided into synchronous and asynchronous (ACLA) [13]. If the interaction of CLA is bounded to its local environment, it is a closed one. If communication happens in the local and global environment, it is an open CLA (OCLA) [12]. The number of LAs in each cell could be one or more due to the application [14]. Finally, CLA's structure could be a grid with the regular structure as in CA, and an irregular one like a tree or graph structure [28]. Figure 2 shows the CLA structure with one LA in each cell. 


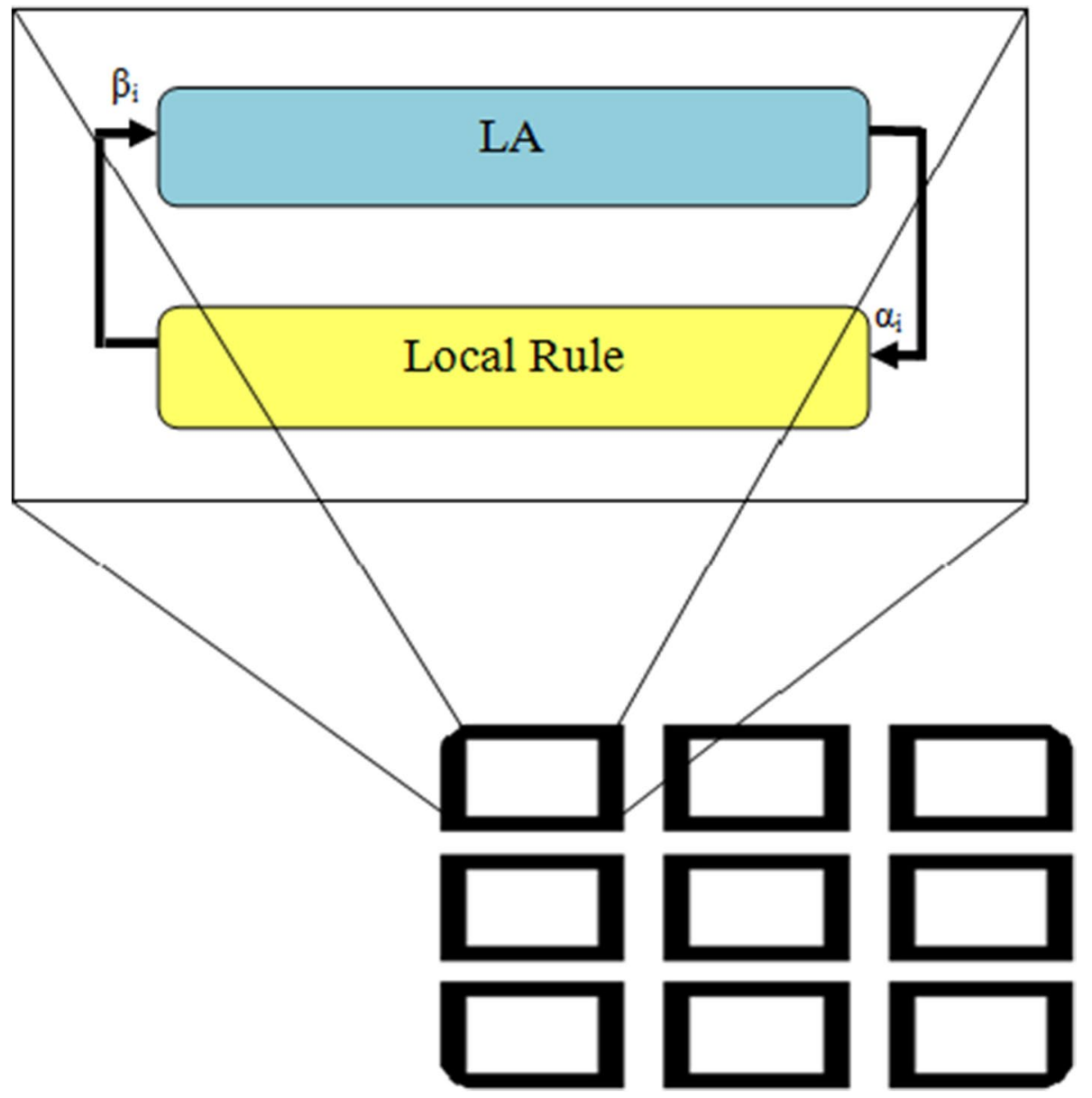

Fig. 2 CLA as a grid structure

\section{The proposed method: RALF}

Under COVID-19 pressures, involving, experimenting, and writing by students based on the correct method and pattern can improve their attitude and writing quality [98, 99]. One of the essential requirements of primary school students is their background to form a writing system for communication. An effective writing system for student engagement is what we call the "student script" and has properties such as expressiveness, legibility, beauty, and correctness of letter and word shapes.

The methodology of this study is to develop RALF as an adaptive reinforcement learning framework for students with dyslexia. A simplified Persian font based on vertical and horizontal lines is created to convenient letter learning. In addition, the reinforcement learning strategy in CLA facilitates synthesizing any given content of letters or words adaptively. Finally, RALF provides an effective platform for children learning via a flexible user interface and other facilities such as multiple-choice exercises and educational games. As a related case study, we applied RALF for dyslexic students in 
a Persian primary school. The results in Sect. 5 show about $27 \%$ improvement in their reading literacy.

The RALF software's architecture comprises Visual Studio C\#, Dot Net Framework 4.5, DevExpress Components, DevExpress Forms, UserControls, C\# programming designs, and regular C\# classes. Users interact with the system by sending programmatic requests, such as a new lesson request or a new exam, to the exam component. It will make the GUI and allow users to activate the software components.

The RALF tool consists of four main parts with some properties or goals, as represented in Fig. 3. When the user clicks the Units button, several lessons are displayed. The Exercise button for each lesson is activated only when the user has viewed all the lesson content. The Exam button is used to assess the user's progress in learning. These components are discussed in the following four subsections.

\subsection{Word training}

As shown in Fig. 1, each unit context, exercise, and exam are presented on a different screen. Each unit contains an image for the lesson context, a baseline for the procedural growth of Persian words using CLA, and a pen to show the graphical sequence of alphabet sketching. Also, the pronunciation of the word is repeated during its procedural modeling.

\section{a) Word generation}

A new procedural modeling algorithm for language reading literacy is proposed based on CLA. The high degree of freedom in procedural modeling often leads to unpredicted results. Combining procedural modeling ideas with popular machine learning methods

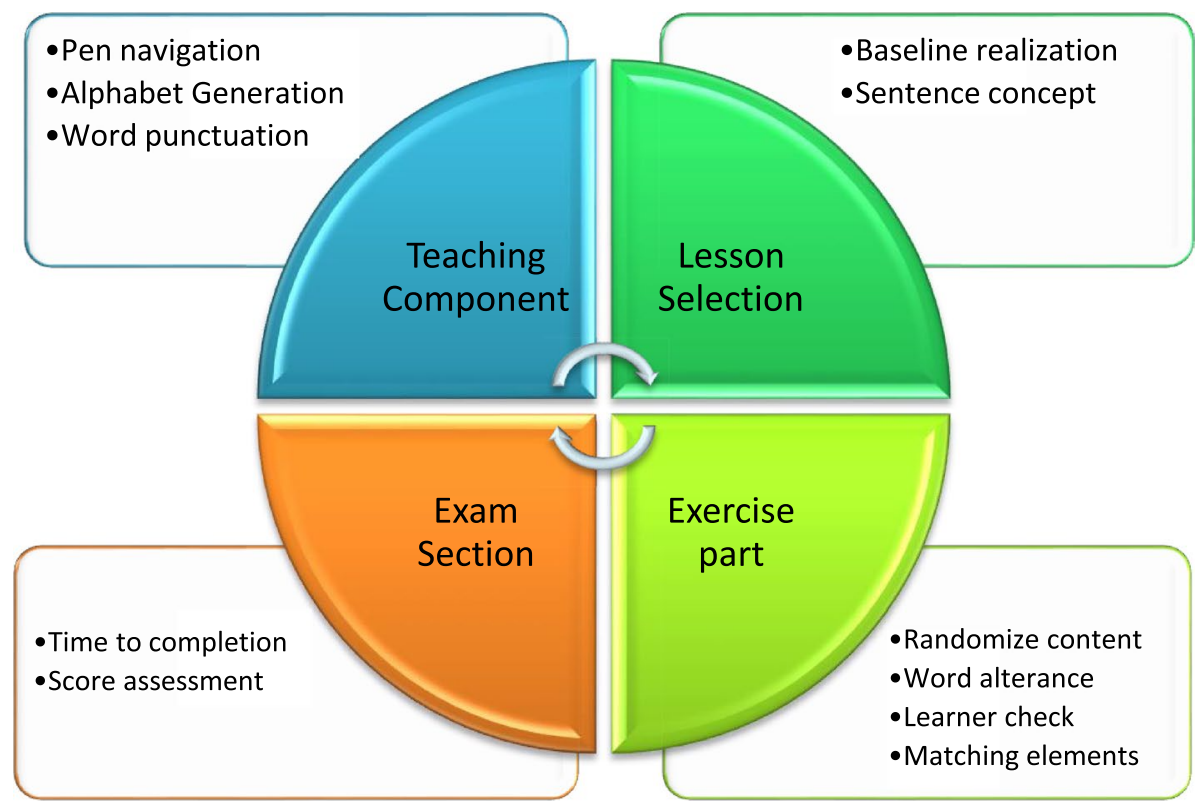

Fig. 3 Educational application component and their capabilities 
is a relatively new solution to alleviate the problem. In this study, a CLA-based procedural algorithm is utilized for generating the Persian alphabet as RALF software. The characteristics of learning in CLA are pretty different from supervised methods. CLA can produce a pattern based on its feedback from the environment. Accordingly, the procedure of alphabet generation could be controlled and leads to the expected results. The CLA components, according to Definition 1 for procedural modeling of Persian alphabets, are as follows:

The set of cells $Z^{d}$ is defined as graphical pixels on the screen. Each cell can take one of the two states from the set $\Phi=\{$ on, off $\}$. The state, "on" indicates colored pixels belonging to the character shape, while the state "off" shows the other pixels. Set A has only one member. Therefore, only one LA resides in each cell. Four neighbors $\mathrm{N}=$ \{right, left, top, down $\}$ is defined for the LA living in each cell. The function $\mathrm{F}$ indicates the response from the environment. The environment is defined as the correct alphabet shape that CLA tries to learn.

The CLA algorithm is as Algorithm CLA-PWG (Persian Word Generation).

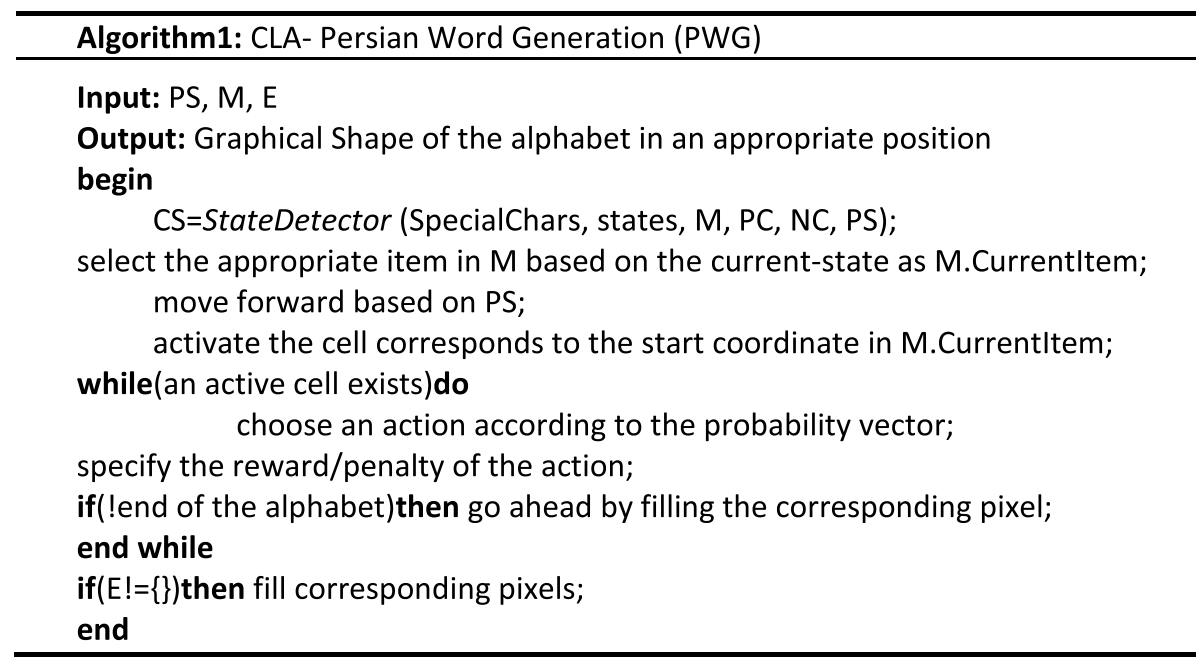

The input set $\{\mathrm{PS}, \mathrm{M}, \mathrm{E}\}$ are as follows:

- PS: previous character's state, i.e., < Initial, Medial, Final, Isolated >

- M: the Main stroke of the character consists of the local coordinates for the alphabet's body

- E: Extensions of the character as secondary and third strokes include \{ single-dot-up, single-dot-down, double-dot-up, double-dot-down, triple-dot-up, triple-dot-down, mad(hat), single-sarkesh (oblique bar), double-sarkesh (two diagonal bars as the second is smaller and placed over the first one), daste (small vertical bar) $\}$. They have delayed strokes after the first pen stroke.

It is worth notifying that Hamzeh, Tashdid, and other peripheral signs are natural for the Arabic language and are not considered here. Also, considering whole Persian letters reveal that more than half of Farsi letters have extensions. 
The input set hereof StateDetector function of the CLA_PWG algorithm is \{SpecialChars, states, PC, NC, M, PS \}, which are described as follows:

- SpecialChars: characters with only two states,i.e., Isolated and Final, because they

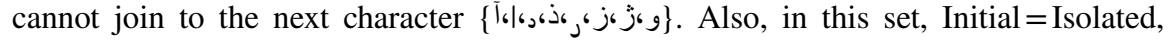
Medial $=$ final. However, the reverse is not true because of the letters $\{b$ b $\}$

- $\quad$ states: $\{$ Initial, Isolated, Medial, final\}

- PC: previous character

- NC: Next character

- M: Main stroke of the character

- PS: former alphabet state

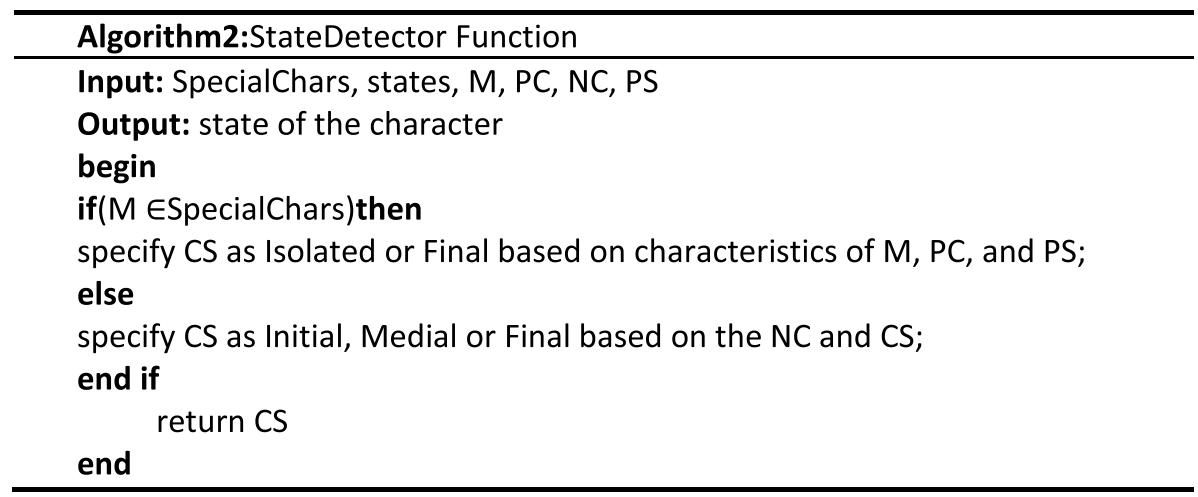

Each of the characters starts from a different start point. Identifying the start point, CLA embarks on its procedure as a moving agent by activating the start cell and trying to move on the screen. A set of four actions \{right, left, top, down $\}$ is defined for LA residing in each cell. The feedback from the environment navigates the agent to a neighboring cell and activates it. The procedure continues until the endpoint of the character shape. All active cells are shown in a different color and generate the character shape. To construct a Persian word, the form of the following character depends on the previous one. We call this notion the character state, which could be one of the \{initial, medial, final, isolated $\}$. This state is defined in the procedure as a constraint.

Due to right to left writing in Persian, after generating a word, a leaving space is necessary on the left side of the last character of the word to the start of the next word to make sentence generation possible.

b) Pen navigation

A graphical icon for a pen is used to depict the pen navigation as the paper's writing process. The movement of this pen proceeds according to the learning process of CLA.

iii) Word pronunciation

The pronunciation of the words is repeatedly played during the procedural generation process. Therefore, understanding and memorizing the meaning of the word become easier. 


\subsection{Lesson Selection}

Figure 1 illustrates the capability of lesson selection. The material for all the lessons is adopted from "Farsi Textbook1" [30] prescribed by the Ministry of Education in Iran for high school primary grades. The main capabilities of this component are as follows:

\section{a) Baseline realization}

Understanding the baseline is crucial while it is an exciting subject in Persian writing.

\section{b) Sentence concept}

The main object here is realizing the sentence concept. The user learns to leave spaces between the words, place them from right to left and put a dot "." at the end.

The good handwriting of primary students, which could be continued in their communication style, depends on these significant factors:

- A proper pattern for the writing system

- A coach familiar with the script principles

- A suitable method for transferring the visual elements

In the COVID-19 era, the research reveals that the writing process's problems could have some untoward effects on students' spirit, attitudes, and social position [82]. Also, lousy handwriting could affect their low scores in education. In contrast, the beautiful script has effects on self-confidence and improving the spiritual senses. The quality of writing is one of the growth factors in enhancing the students' education as well. Other significant effects of good handwriting are as follows:

Easy reading through the excellent script motivates the students to read the texts and promotes their learning rate.

Easy writing by which fluent and straightforward writing is performed could lead to pleasure from their writing process.

An effective tool for interaction and communication in society and motivate their interest in writing.

Therefore, the Ma'qeli script could play an essential role in teaching the alphabet in primary schools. The script's fundamental principles keep its potential for matching with any language letters other than Persian/Arabic, such as English or even Chinese. Figure 4 illustrates the Stakeholder engagement for orthography learning.

\subsection{Exercise as a game}

According to Fig. 3, a matching word-to-picture game is provided for exercise. Every time the matching process occurs correctly, the pronunciation of the word is played [9]. Furthermore, the total time and the number of wrong tries are computed as evaluation measures at the end of the training. The capabilities of the exercise component are as follows:

\section{a) Randomize content}




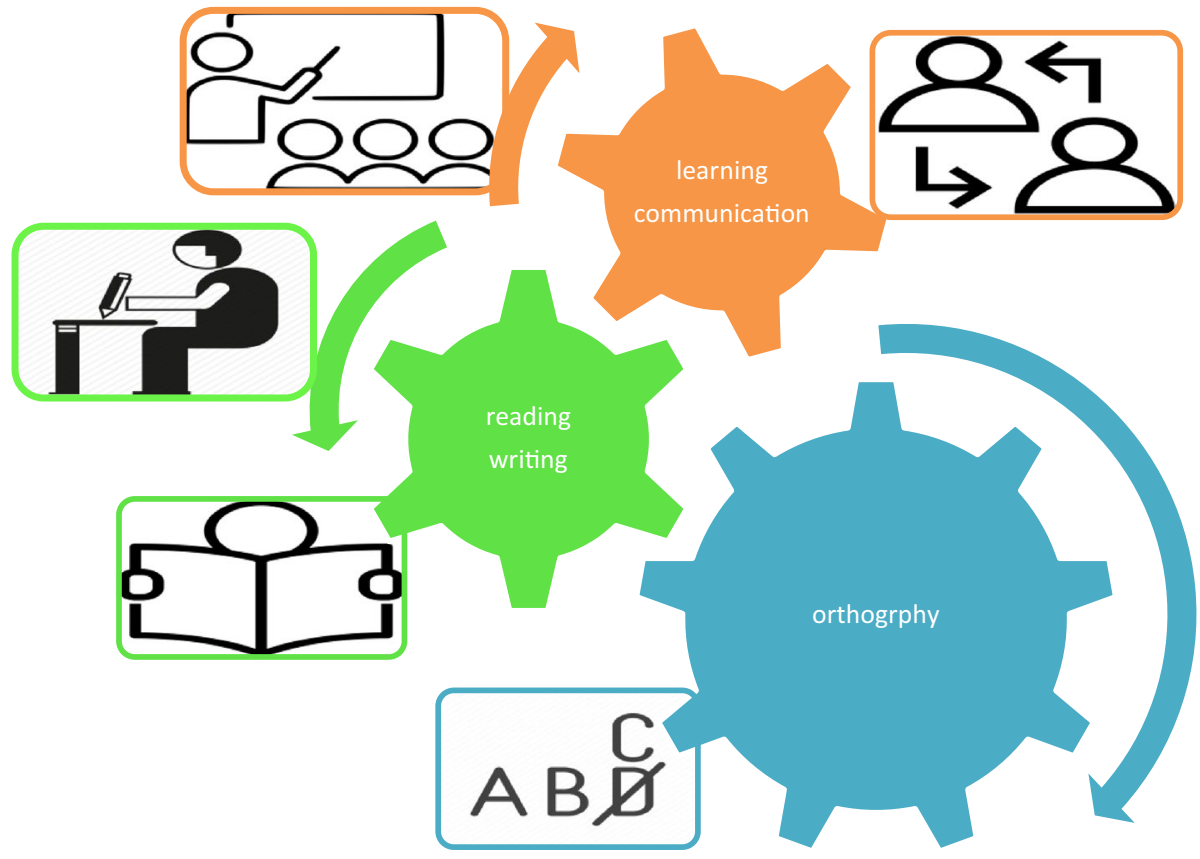

Fig.4 Stakeholder engagement in orthography learning

The content of the game consists of some Persian words and some related pictures. The materials and their layout are generated randomly in each run. Also, there is an option to select the level of the game.

\section{b) Matching the words}

The user should click on the hidden pictures, and then its content could be shown if two related contents include the training picture and its related Persian words, the user scores.

\section{iii) Word utterance}

When the user takes a score, the pronunciation of the word is played. In other words, the user understands that they did well, and the meaning of the word is reviewed for them like a gamification procedure [86].

\section{iv) Learner checker}

When the game is finished, the overall score and the whole game playing are demonstrated. Thus the user could have a self-evaluation of their learning.

\subsection{Multimedia exam}

Finally, a four-choice exam is provided to assess the user. In this case, a picture from the set of previously taught content is shown with three incorrect and only one correct word. At the end of the exam, the gain score is computed and displayed. 
a) Time to completion

The time for completing the test is computed. Thus, it can assess the action speed of the user.

b) Score assessment

At the end of the game, the obtained scores by the user are shown. Also, a detailed description of the user's answers is available.

\subsection{Application interface}

RALF application has a bilingual interface. The design of the main form is done by dividing it into two sections. The top section contains the icons and menus, and the down part for showing the contents. A variety of facilities are predicted in the lists. For example, it sets the language that includes English and Persian for the current version of the application. Also, selecting the lessons, word training, exercise, and tests could be done in the screen's section. Figure 5 shows the interface of the RALF application.

\subsection{Game and Exam}

Running the RALF application depicts the operation of the software. Figure 6 demonstrates the lesson section of the RALF application. In each lesson, a selected lesson from the textbook1is demonstrated that the lesson contents' procedural modeling proceeds. Figure 3 shows the operation of word training. The words are generated by CLA related to the baseline. Also, the word pronunciation and movement of the pen is shown.

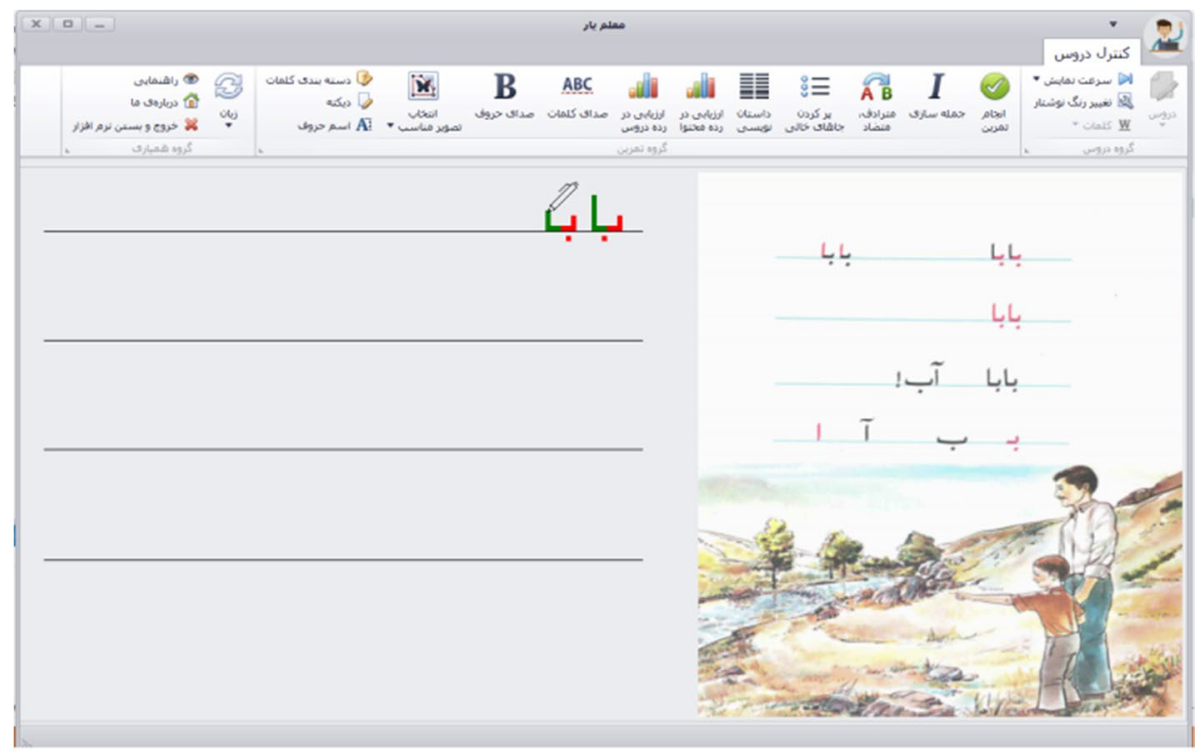

Fig. 5 The RALF software interface and pen-navigator. The Persian word means father 


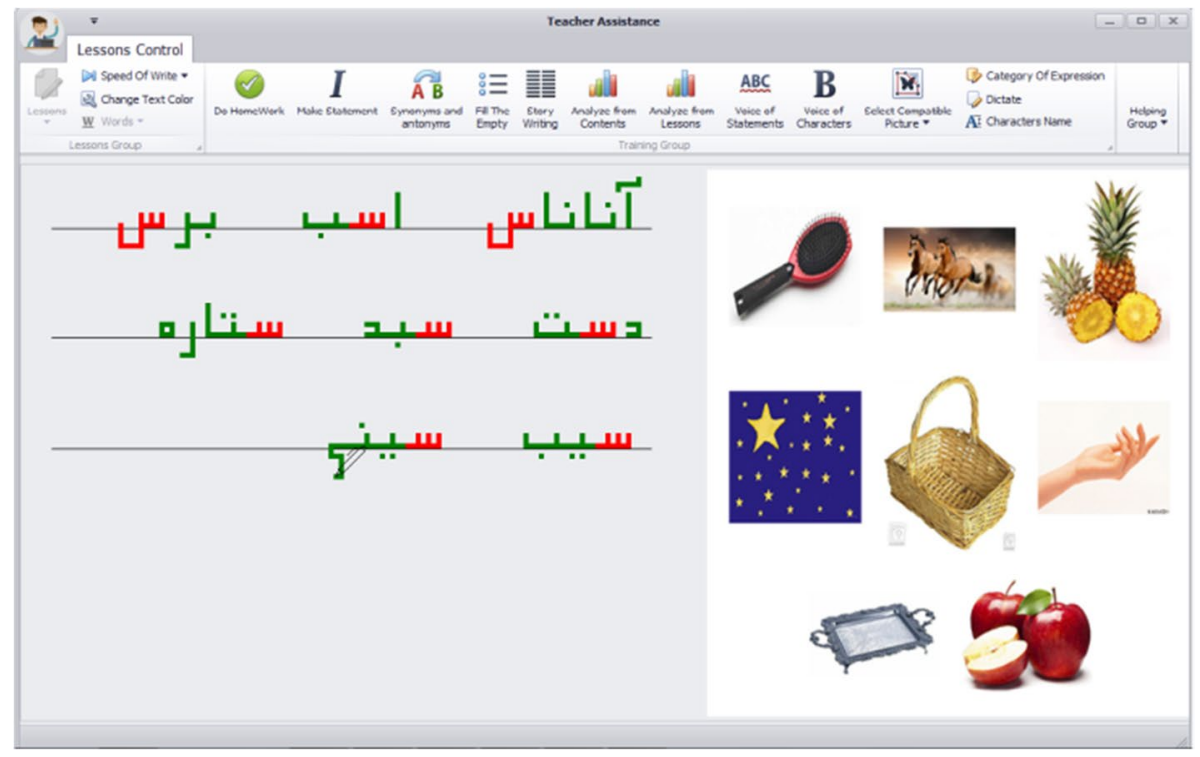

Fig. 6 The RALF software environment for unit "س." The Persian words mean respectively pineapple, horse, brush, hand, basket, star, apple, and tray from right to left and up to down

Figure 7 illustrates the operation of exercise as a game. In Fig. 7, the game is played partially. The hidden content and the played one can be seen as well.

Figure 8 shows the structure of a word test. A picture considers a four-choice question, and the user should select one of the presented choices and scroll the window to see the next issue.

The questions are provided in two main categories. The first category is based on material thought. Therefore, the users see four choices that are all familiar to them. The second category is free content. Thus, the user sees four options in which the only one is taught till now, and the others are not. These two distinct categories help evaluate the user in two leading psychological educations: concept detection and familiar identification. In the end, the overall score obtained by the user is displayed.

\section{Results and Evaluation}

This section aims to evaluate how procedural modeling affects learning. An evaluation of the two groups of students is applied to reach this aim. Outcomes of the tests are computed to find the best method. All participants were Iranian, including two classes of primary school. A total of 10 students volunteered in the study. One type was assigned to the experimental group and the other to the control group. The experimental group includes five students tested by the RALF application, while the flash learning cards guided the control group with five students.

Figure 9 shows the procedure of the experiment. At first, all students took a pretest with the textbook context. During the learning process, the control group participated in a paper-and-pencil traditional class, while the experimental group learned by the RALF application for the same course material. After the learning process was over, the students 


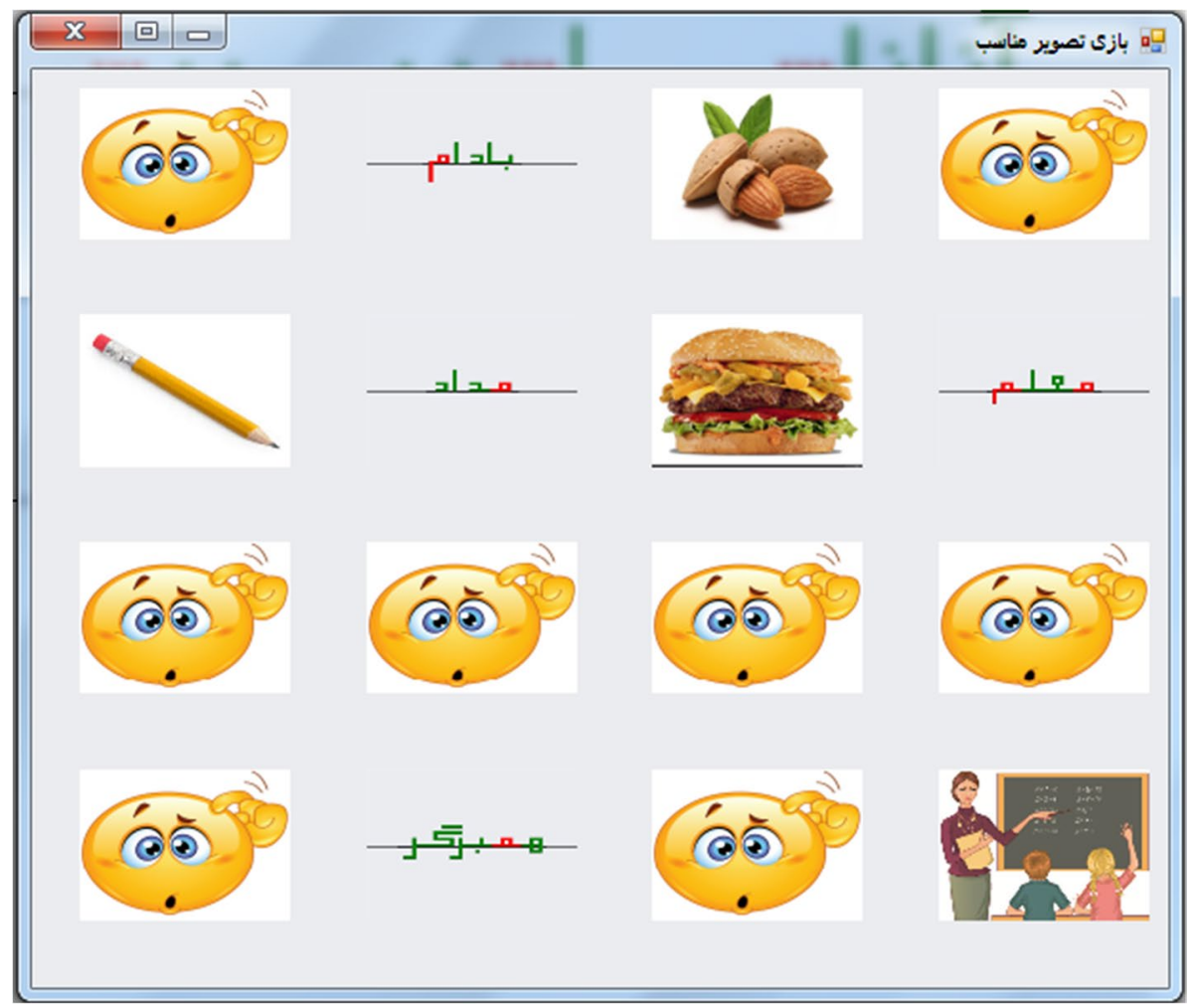

Fig. 7 TheRALF software environment for exercises. The Persian words mean respectively almond, teacher, pencil, and hamburger from right to left and up to down

participated in a post-test that is also based on the textbook. After the post-test activity, the students completed the attitudes, learning, and acceptance questionnaire.

A questionnaire was prepared to evaluate attitude, learning, and acceptance of the RALF application. The questionnaire items were adapted for this study based on the frequent questions in the field [74] and are presented in Table 3. Five choices were recommended in the questionnaire, including "very high," "a lot," "somehow," "a little," and "not at all."

The mean scores were analyzed in an independent t-test process $(\mathrm{p} \leq 0.05, \mathrm{df}=37)$ to examine the possibility of difference between the experimental and control groups. The results of ANOVA based on total reading scores were used to investigate the difference between experimental and control groups in terms of the students' ability in their reading. A paired t-test was conducted to explore the effect of existing different instructions in reading skill development. Furthermore, the total scores of relating items in the questionnaires were taken to account to consider the self-assessment skills. By an independent t-test, these scores were transformed to a standard percentage.

The independent t-test results are demonstrated in Table 4. This analysis shows that there is not a significant difference in achievement level between the two groups.

The resulting feedback reveals that the RALF system had similar effects on primary school students' reading achievement levels. However, a pair-wise comparison 


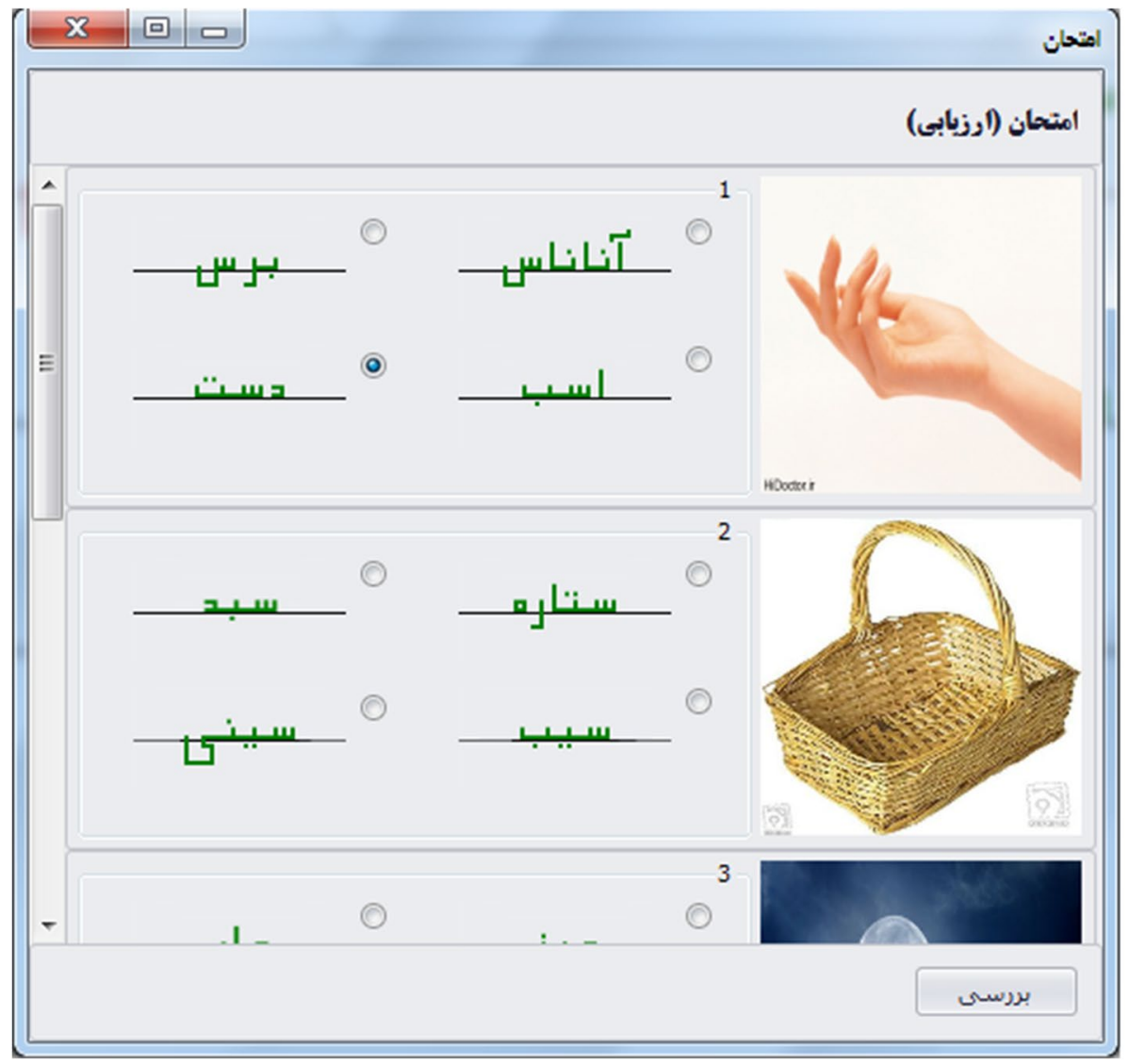

Fig. 8 TheRALF software environment for exams. The Persian words mean respectively pineapple, brush, horse, hand, star, basket, apple, and tray from right to left and up to down

in Table 4 between the experimental and control groups in terms of the means demonstrates that the experimental group achieved higher scores than the control group. Also, the ANOVA test results in Fig. 10 show a considerable difference between the two groups in handling reading elements. In all categories, the experimental group students reached higher scores than the students in the control group.

The statistics of paired samples implied that the reading skills of dyslexic students in the control group did not improve significantly during the instruction course. However, the concluding remarks from the experimental group were not the same. The difference between the former and the latter was significant.

The group statistics in Table 5 determined that there was no significant difference between the two groups. Therefore, using RALF for reading activity had no substantial effect on the experimental group's assessment features compared to the control group. However, comparing the mean scores indicates that working with RALF had made students more capable of self-learning. 


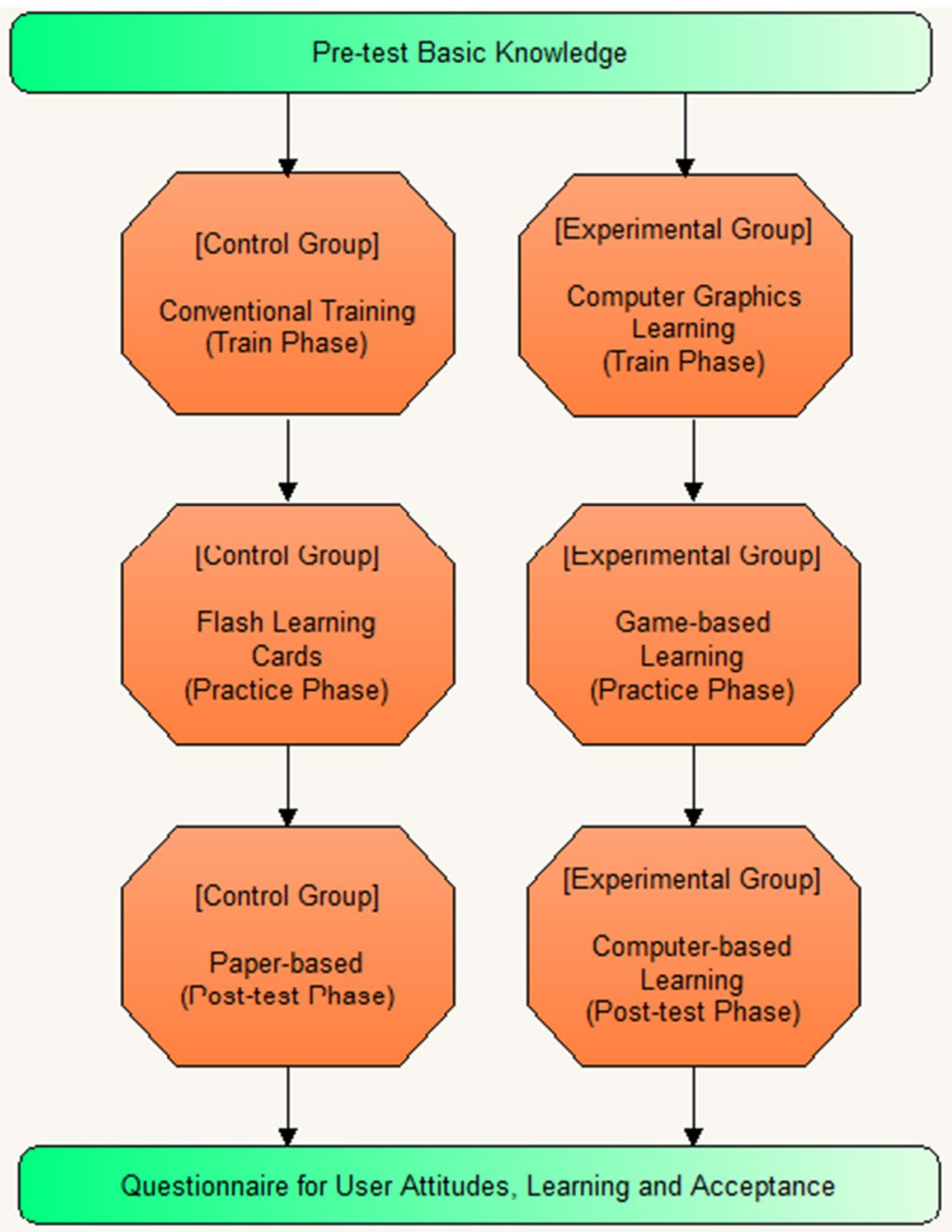

Fig. 9 Experiment process diagram

Table 3 Questionnaire items

Questions

Are you enjoying PTA?

Is the PTA easy to try?

Do you ever confuse with this software?

Do you attempt to act by PTA well?

Do you focus on the learning task?

Do you complete the learning task?

Do you discourage yourself when faced with an obstacle?

Do you consider the PTA to improve your learning? 
Table 4 The independent t-test of the dyslexic students

\begin{tabular}{llllll}
\hline Group & $\mathrm{N}$ & Mean & S.D & t-value & sig \\
\hline Experimental & 20 & 81.37 & 16.14 & 0.19 & 0.69 \\
Control & 20 & 54.77 & 14.23 & 0.19 & 0.69 \\
\hline
\end{tabular}

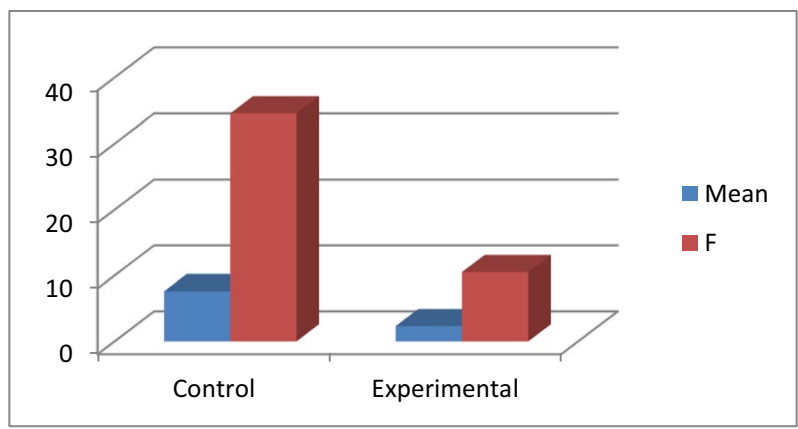

Fig. 10 ANCOVA results of control and experimental groups sig.:(0.000, 0.000), df: $(1,9)$

Table 5 The statistics of the groups in individual-assessment

\begin{tabular}{llllll}
\hline Group & $\mathrm{N}$ & Mean & S.D & t-value & sig \\
\hline Experimental & 20 & 92.12 & 11.55 & 0.86 & 0.33 \\
Control & 20 & 65.68 & 14.28 & 0.86 & 0.33 \\
\hline
\end{tabular}

\section{Discussion and Challenges}

\subsection{Discussion}

Using RALF did not significantly affect the students' reading skills level in the two groups at the end of the instruction process. However, the experimental group gained a higher mean score, implying that RALF is more beneficial for progressing reading skills or making it more accurate. This score difference might be due to the immediate feedback, which is the nature of the computer aids. During the use of RALF, any mistake of the user was determined. These determinations could help the students to be more aware of the correct pronunciation to improve their reading. The role of the game exams provided by RALF should not be ignored. The students could see the words and their related shapes (Fig. 6). It can be claimed that this game increases their vocabulary skill and indirectly influences their reading scores.

The pen-navigator (Fig. 5) in remembering the structure of the alphabets and its positive effects on their reading skill should also be considered. Another reason for the mean difference between the two groups can be attributed to detecting the word elements by making parts in RALF in the experimental group. It means that their orthography knowledge accuracy had influenced their reading significantly compared with the students in traditional classes at school. It should be noted that the random selection 
of the students in the division of two heterogeneous groups may affect the results. The homogeneous groups with the same treatment may cause a significant difference.

The results in Fig. 10 revealed that the experimental group's reading accuracy was higher than that of the control group. This achievement could be due to the immediate feedback of the RALF system. Therefore, the students receiving such feedback became aware of their mistakes and tried to improve themselves.

The results of the t-test in Table 4 implied that the individual assessment skills of the two groups had no significant difference. Therefore, it can be said that the human-computer interaction did not significantly improve autonomy and self-learning. On the other hand, the experimental group's higher mean scores may reveal that the learners could be aware of their difficulties using the RALF system as an awareness-raising tool fostering by immediate feedback. But the learners in the control group deprived of receiving such feedback from the teacher. Consequently, the experimental group students were able to achieve internal feedback and test their reading capability.

The results in Table 5 of the paired t-test performed between the pretest and post-test of each group indicated that the students significantly improved their reading skills in the experimental group. The comparisons demonstrated the higher scores of these students in the post-test. The considerable difference in the final scores is due to the effect of CALL in language classes [74]. It seems that by using RALF, the students became more aware of their difficulties in the reading area. Therefore, the difference might be according to the nature of the interaction between the student and the RALF system.

The main finding of this research is that RALF could improve the potential ability of dyslexic students in reading velocity. In addition, it improves the components of reading such as single word recognition, chain of words recognition, reading comprehension, word comprehension, and naming the pictures. Because of the simple and easy usage of RALF, the educational process is facilitated. Consequently, the students could identify their mistakes, correct them, select the best choice, and empower their self-awareness and self-confidence by receiving immediate encouragement via RALF. Therefore, there is a meaningful difference in reading scores between the experimental and control groups. The interpretation of obtained results is that multimedia education could enrich the children learning by response time reduction and immediate feedback. In other words, RALF motivates the students to continue doing their homework and actively involve the learning or even like to do it again. The usage of the proposed framework as a complementary for traditional trading has more effectiveness as well.

However, the current research is applied only to primary school students. Therefore, the generalizations of the result should perform cautiously. Another limitation of this work is the loss of follow-up course and gender segregation during the experiment.

The findings describe the potential of this framework to extend for dictation, educational games, problem-solving, word processing, and spelling. Finally, RALF could be modified to enrich the features for treating other learning disorders like dysgraphia, dyscalculia, cross-lateral, and hyperactivity.

\subsection{Challenges}

The Ma'qeli challenges in terms of orthography learning in computer-assisted learning tools are illustrated in Fig. 11. These challenges are classified as follows: 


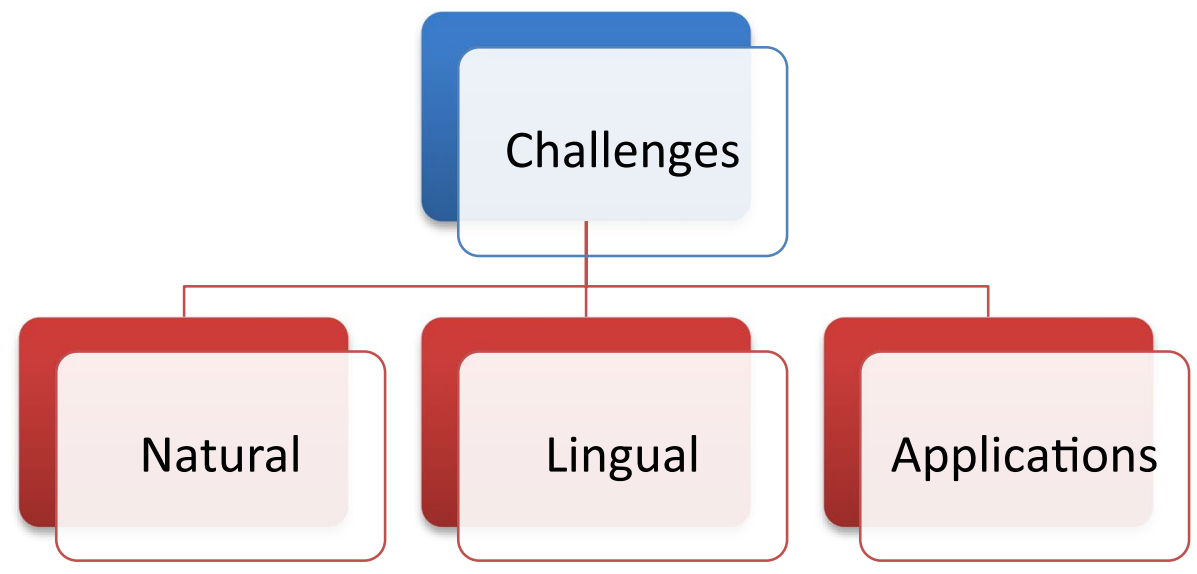

Fig. 11 Challenges of Ma'qeli representation

a) Natural challenges: natural challenges are related to the natural properties of the Ma'qeli script. The representation of letters, words, and points in the Ma'qeli script is a challenging area. Furthermore, in many cases, there is a need to vitiate the writing rules for reasonable representation. Also, sometimes there is a need for additional space in representing the words. For example, the representation of "عول" need more space in comparison to " זول" because of the required space for points. Therefore the overall glyph of the character should be extended [54].

b) Lingual challenges: The lingual difficulties are related to modeling the letters of different languages. In complicated letters like the Chinese language, there is a need for many strokes. Also, in some languages, modeling the letters in Ma'qeli leads to an equal representation for two or more different letters. For example, in English, Ma'qeli representation of ' $U$ ' and ' $V$ ' are identical. One idea for considering the difference is adding some strokes like serif fonts for $\mathrm{V}$.

Another challenge is the similarity between several letters and digits. For instance, in Persian/Arabic, there is a single Ma'qeli representation for the letter' I' (Alif) and the digit '1' (one). Also, in English, the letter 'l' (El) is similar to '1' (one). Again, a straightforward solution is adding more strokes for the difference.

iii) Application challenges: Application challenges point to the requirements in the application area. The algorithmic generation of the Ma'qeli script is a challenging area in which some research is investigated [54, 75]. Furthermore, this script's detection and recognition is an exciting area of study $[2,7,35]$.

\section{Conclusion}

Providing a straightforward platform for alphabet learning in the COVID-19 outbreak is challenging in communication and education [4]. Digital tutoring software with artificial intelligence facilitates learning for educators [32, 83]. However, the lack of a simple font representation model still leads to difficulties for both educators with dyslexia $[69,87]$ and 
pedagogical software developers [61]. Furthermore, although several researchers have performed a detailed evaluation of children's handwriting [24, 25], even though fuzzy models [80], they have not provided a graphical learning process to empower their realization of alphabet writing.

In this research, we proposed RALF as a learning framework for students with dyslexia to improve their reading literacy. RALF generates each letter by a simple font through a reinforcement cycle considering the Persian writing rules such as baseline, right-to-left, and correct alphabet shape in various forms. Additionally, RALF generates any given Persian word online, considering the accurate cursiveness of all letters. Finally, the flexible user interface of RALF prepares various writing speeds and colors of font beside practical exercises through multiple-choice tests and educational games. The results of applying RALF show significant improvement in the reading skill of students with dyslexia.

Extending the ability of RALF to teach other popular languages to students with reading difficulties is future work. Another area of research is also enhancing the RALF facilities as teacher-assisted software such as spelling correction by natural language processing through transfer learning in neural networks.

\section{References}

1. Ahuja M, Loeb AL (1995) Tessellations in Islamic calligraphy. Leonardo 28:41-45

2. Al Abodi J, Li X (2014) An effective approach to offline Arabic handwriting recognition. Comput Electr Eng 40:1883-1901

3. Alghabban WG, Salama RM, Altalhi AH (2017) Mobile cloud computing: An effective multimodal interface tool for students with dyslexia. Comput Human Behav 75:160-166

4. Ali S, Hafeez Y, Abbas MA, et al (2021) Enabling remote learning system for virtual personalized preferences during COVID-19 pandemic. Multimed Tools Appl 1-27

5. Aljojo N (2020) Understanding the sequence of learning in Arabic text-saudi Arabian dyslexics and learning aid software. Educ Technol Soc 23:47-60

6. Almaiah MA, Al-Khasawneh A, Althunibat A (2020) Exploring the critical challenges and factors influencing the E-learning system usage during COVID-19 pandemic. Educ Inf Technol 1

7. Arifoglu D, Sahin E, Adiguzel H et al (2015) Matching Islamic patterns in Kufic images. Pattern Anal Appl 18:601-617. https://doi.org/10.1007/s10044-014-0437-z

8. Bastanfard A, Fazel M, Kelishami AA, Aghaahmadi M (2009) A comprehensive audio-visual corpus for teaching sound Persian phoneme articulation. Conf Proc - IEEE Int Conf Syst Man Cybern 169-174. https://doi.org/10.1109/ICSMC.2009.5346591

9. Bastanfard A, Aghaahmadi M, Fazel M, Moghadam M (2009) Persian viseme classification for developing visual speech training application. In: Pacific-Rim Conference on Multimedia. Springer, pp 1080-1085

10. Bastanfard A, Rezaei NA, Mottaghizadeh M, Fazel M (2010) A novel multimedia educational speech therapy system for hearing impaired children. In: Pacific-Rim Conference on Multimedia. Springer, pp 705-715

11. Beigy H, Meybodi MR (2004) A mathematical framework for cellular learning automata. Adv Complex Syst 7:295-319

12. Beigy H, Meybodi MR (2007) Open synchronous cellular learning automata. Adv Complex Syst 10:527-556

13. Beigy H, Meybodi MR (2008) Asynchronous cellular learning automata. Automatica 44:1350-1357

14. Beigy H, Meybodi MR (2010) Cellular learning automata with multiple learning automata in each cell and its applications. IEEE Trans Syst Man, Cybern Part B 40:54-65

15. Benmarrakchi FE, El Kafi J, Elhore A (2017) User modeling approach for dyslexic students in virtual learning environments. Int J Cloud Appl Comput 7:1-9

16. Berget G, Mulvey F, Sandnes FE (2016) Is visual content in textual search interfaces beneficial to dyslexic users? Int J Hum Comput Stud 92:17-29

17. Blom E, van Dijk C, Vasić N et al (2017) Textese and use of texting by children with typical language development and Specific Language Impairment. Comput Human Behav 66:42-51 
18. Botvinick M, Ritter S, Wang JX et al (2019) Reinforcement learning, fast and slow. Trends Cogn Sci 23:408-422

19. Carlotto T, Jaques PA (2016) The effects of animated pedagogical agents in an English-as-a-ForeignLanguage learning environment. Int J Hum Comput Stud 95:15-26

20. Cordón O, del Jesús MJ, Herrera F, Lozano M (1999) MOGUL: A methodology to obtain genetic fuzzy rule-based systems under the iterative rule learning approach. Int J Intell Syst 14:1123-1153

21. Davidson R, Hopely R (1997) Arabic and Persian OCR training and test data sets. In: Proc. of Symp. on Document Image Understanding Technology, April. Citeseer, pp 200-202

22. Daloiso M (2017) Supporting learners with dyslexia in the ELT classroom. Oxford University Press

23. Dehshibi MM, Shirmohammadi A, Adamatzky A (2015) Pattern formation using L-systems: A case study in forming Neyname's words. In: AIP Conference Proceedings. AIP Publishing LLC, p 580015

24. Dimauro G, Bevilacqua V, Colizzi L, Di Pierro D (2020) TestGraphia, a software system for the early diagnosis of dysgraphia. IEEE Access 8:19564-19575

25. Drotár P, Dobeš M (2020) Dysgraphia detection through machine learning. Sci Rep 10:1-11

26. Edwards A, Edwards C, Westerman D, Spence PR (2019) Initial expectations, interactions, and beyond with social robots. Comput Human Behav 90:308-314

27. Emtiyaz S, Keyvanpour M (2012) Customers behavior modeling by semi-supervised learning in customer relationship management. arXiv Prepr arXiv12011670

28. Esnaashari M, Meybodi MR (2015) Irregular cellular learning automata. IEEE Trans Cybern 45:1622-1632

29. Ezatzadeh S, Keyvanpour MR (2019) ViFa: an analytical framework for vision-based fall detection in a surveillance environment. Multimed Tools Appl 78:25515-25537

30. Farhady H, Tavassoli K (2013) Assessing Farsi companion to Lang Assess 4:1790-1798

31. Franceschini S, Bertoni S (2019) Improving action video games abilities increases the phonological decoding speed and phonological short-term memory in children with developmental dyslexia. Neuropsychologia 130:100-106

32. Gelsomini M, Spitale M, Garzotto F (2021) Phygital interfaces for people with intellectual disability: an exploratory study at a social care center. Multimed Tools Appl 1-32

33. Hagelkruys D, Böhm C, Motschnig R et al (2016) Adapting a stand-alone computerized cognitive test battery for online use-a case-study in the context of users with special needs. Comput Human Behav 63:757-768

34. Hassan S, Waheed H, Aljohani NR et al (2019) Virtual learning environment to predict withdrawal by leveraging deep learning. Int J Intell Syst 34:1935-1952

35. Hajihashemi V, Ameri MMA, Gharahbagh AA, Bastanfard A (2020) A pattern recognition based Holographic Graph Neuron for Persian alphabet recognition. In: 2020 International Conference on Machine Vision and Image Processing (MVIP). IEEE, pp 1-6

36. Jothi Prabha A, Bhargavi R (2019) Prediction of dyslexia from eye movements using machine learning. IETE J Res 1-10

37. Kardan AA, Aziz M, Shahpasand M (2015) Adaptive systems: a content analysis on technical side for e-learning environments. Artif Intell Rev 44:365-391

38. Kastner MA, Ide I, Nack F et al (2020) Estimating the imageability of words by mining visual characteristics from crawled image data. Multimed Tools Appl 79:18167-18199

39. Keyvanpour MR, Azmi R, Tabatabai ZSM, Abdolhosseini Z (2015) Handwriting Persian character recognition using optimized structural elements. Glob J Inf Technol 4:

40. Keyvanpour MR, Vahidian S, Ramezani M (2020) HMR-vid: a comparative analytical survey on human motion recognition in video data. Multimed Tools Appl 79:31819-31863

41. Keyvanpour MR, Khanbani N, Boreiry M (2021) A secure method in digital video watermarking with transform domain algorithms. Multimed Tools Appl 80:20449-20476

42. Keyvanpour MR, Khanbani N, Aliniya Z (2021) Detection of individual activities in video sequences based on fast interference discovery and semi-supervised method. Multimed Tools Appl 80:13879-13910

43. Khan FA, Shahzad F, Altaf M (2019) Fuzzy based approach for adaptivity evaluation of web based open source learning management systems. Cluster Comput 22:7099-7109

44. Knoop-van Campen CAN, Segers E, Verhoeven L (2020) Effects of audio support on multimedia learning processes and outcomes in students with dyslexia. Comput Educ 150:103858

45. Kumar M, Jindal MK, Sharma RK (2017) Offline handwritten Gurmukhi character recognition: analytical study of different transformations. Proc Natl Acad Sci India Sect A Phys Sci 87:137-143

46. Kumar M, Jindal SR, Jindal MK, Lehal GS (2019) Improved recognition results of medieval handwritten Gurmukhi manuscripts using boosting and bagging methodologies. Neural Process Lett 50:43-56 
47. Kumar M, Jindal MK, Sharma RK, Jindal SR (2020) Performance evaluation of classifiers for the recognition of offline handwritten Gurmukhi characters and numerals: a study. Artif Intell Rev 53:2075-2097

48. Kumar M, Jindal MK, Sharma RK, et al (2021) Improved recognition results of offline handwritten Gurumukhi characters using hybrid features and adaptive boosting. Soft Comput 1-13

49. Lundberg I, Olofsson $\AA$ (1993) Can computer speech support reading comprehension? Comput Human Behav 9:283-293

50. Meybodi MR, Beigy H, Taherkhani M (2003) Cellular learning automata and its applications. Sharif J Sci Technol 19:54-77

51. Minoofam SAH, Bastanfard A (2008) A novel algorithm for generating Muhammad pattern based on cellular automata. In: WSEAS International Conference. Proceedings. Mathematics and Computers in Science and Engineering. WSEAS

52. Minoofam SAH, Bastanfard A (2010) Square kufic pattern formation by asynchronous cellular automata. In: International Conference on Cellular Automata. Springer, pp 79-82

53. Minoofam SAH, Bastanfard A (2017) Learning Automata: A Comparative Analysis of Estimator Algorithms. 2017 Iran Conf Electr Eng

54. Minoofam SAH, Dehshibi MM, Bastanfard A, Eftekhari P (2012) Ad-hoc Ma'qeli script generation using block cellular automata. J Cell Autom 7:321-334

55. Minoofam SAH, Ahmadi J, Kanan HR (2015) A comparative review on nondeterministic sets for association rule mining. In: 2015 4th Iranian Joint Congress on Fuzzy and Intelligent Systems (CFIS). IEEE, pp 1-5

56. Minoofam SAH, Bastanfard A, Keyvanpour MR (2021) TRCLA: A Transfer Learning Approach to Reduce Negative Transfer for Cellular Learning Automata. IEEE Trans Neural Networks Learn Syst

57. Modhej N, Bastanfard A, Teshnehlab M, Raiesdana S (2020) Pattern Separation Network Based on the Hippocampus Activity for Handwritten Recognition. IEEE Access

58. Moradi M, Keyvanpour M (2015) CAPTCHA and its alternatives: a review. Secur Commun Networks 8:2135-2156

59. Moradi M, Keyvanpour MR (2020) A novel CAPTCHA scheme based on facial expression reconstruction. Int J Electron Bus 15:368-388

60. Movahedi Z, Bastanfard A (2021) Toward competitive multi-agents in Polo game based on reinforcement learning. Multimed Tools Appl 1-21

61. Mulenga EM, Marbán JM (2020) Prospective teachers' online learning Mathematics activities in the age of COVID-19: A cluster analysis approach. EURASIA J Math Sci Technol Educ 16:em1872

62. Mushtaq F, Misgar MM, Kumar M, Khurana SS (2021) UrduDeepNet: offline handwritten Urdu character recognition using deep neural network. Neural Comput Appl 1-24

63. Narang SR, Kumar M, Jindal MK (2021) DeepNetDevanagari: a deep learning model for Devanagari ancient character recognition. Multimed Tools Appl 80:20671-20686

64. Narendra KS, Thathachar MAL (2012) Learning automata: an introduction. Courier Corporation

65. Nguyen CT, Nguyen HT, Mita K, Nakagawa M (2019) Robust and real-time stroke order evaluation using incremental stroke context for learners to write Kanji characters correctly. Pattern Recognit Lett 121:140-149

66. Ojeda-Castelo JJ, Piedra-Fernandez JA, Iribarne L (2021) A device-interaction model for users with special needs. Multimed Tools Appl 80:6675-6710

67. Parray IR, Khurana SS, Kumar M, Altalbe AA (2020) Time series data analysis of stock price movement using machine learning techniques. Soft Comput 24:16509-16517

68. Peng X, Chen H, Wang L, Wang H (2018) Evaluating a 3-D virtual talking head on pronunciation learning. Int J Hum Comput Stud 109:26-40

69. Phelps C (2021) Opening the Conversation: The Development of a Faculty-Facing Module on Teaching Students With Dyslexia. IEEE Trans Prof Commun

70. Pise A, Vadapalli H, Sanders I (2020) Facial emotion recognition using temporal relational network: an application to E-learning. Multimed Tools Appl 1-21

71. Redondo RPD, Rodríguez MC, Escobar JJL, Vilas AF (2021) Integrating micro-learning content in traditional e-learning platforms. Multimed Tools Appl 80:3121-3151

72. Rello L, Baeza-Yates R (2016) The effect of font type on screen readability by people with dyslexia. ACM Trans Access Comput 8:1-33

73. Rohani AR, Bastanfard A (2016) Algorithm for persian text sentiment analysis in correspondences on an e-learning social website. J Res Sci Eng Technol 4:11-15

74. Rubio G, Navarro E, Montero F (2014) APADYT: a multimedia application for SEN learners. Multimed Tools Appl 71:1771-1802 
75. Sabetfard M, Nadimi H (2019) Generating Square Kufic Patterns Using Cellular Automata. Nexus Netw J 1-16

76. Sakkal M (2018) Intersecting squares: applied geometry in the architecture of Timurid Samarkand. J Math Arts 12:65-95

77. Salehi F, Keyvanpour MR, Sharifi A (2021) GT2-CFC: General type-2 collaborative fuzzy clustering method. Inf Sci (Ny) 578:297-322

78. Salehi F, Keyvanpour MR, Sharifi A (2021) CFC: semi-supervised collaborative fuzzy clustering method. J Ambient Intell Humaniz Comput 1-27

79. Shaker N, Liapis A, Togelius J, et al (2016) Constructive generation methods for dungeons and levels. In: Procedural Content Generation in Games. Springer, pp 31-55

80. Simonnet D, Anquetil E, Bouillon M (2017) Multi-criteria handwriting quality analysis with online fuzzy models. Pattern Recognit 69:310-324

81. Simonnet D, Girard N, Anquetil E et al (2019) Evaluation of children cursive handwritten words for e-education. Pattern Recognit Lett 121:133-139

82. Sintema EJ (2020) Effect of COVID-19 on the performance of grade 12 students: Implications for STEM education. Eurasia J Math Sci Technol Educ 16:em1851

83. Sipior JC (2020) Considerations for Development and Use of AI in Response to COVID-19. Int J Inf Manage 102170

84. Smith C, Hattingh MJ (2020) Assistive Technologies for Students with Dyslexia: A Systematic Literature Review. In: International Conference on Innovative Technologies and Learning. Springer, pp 504-513

85. Srivastava B, Haider MTU (2017) Personalized assessment model for alphabets learning with learning objects in e-learning environment for dyslexia. J King Saud Univ Inf Sci

86. Takbiri Y, Amini A, Bastanfard A (2019) A structured gamification approach for improving children's performance in online learning platforms. In: 2019 5th Iranian Conference on Signal Processing and Intelligent Systems (ICSPIS). IEEE, pp 1-6

87. Taskov T, Dushanova J (2021) Small-World Propensity in Developmental Dyslexia After Visual Training Intervention. In: Intelligent Computing. Springer, pp 233-258

88. Thomas MSC, Rogers C (2020) Education, the science of learning, and the COVID-19 crisis. Prospects 1

89. Truong HM (2016) Integrating learning styles and adaptive e-learning system: Current developments, problems and opportunities. Comput Human Behav 55:1185-1193

90. Ullah F, Wang J, Farhan M et al (2020) Plagiarism detection in students' programming assignments based on semantics: multimedia e-learning based smart assessment methodology. Multimed Tools Appl 79:8581-8598

91. Waner S, Hastings HM (1988) History dependent stochastic automata: a formal view of evolutionary learning. Int J Intell Syst 3:19-34

92. Waters TEA, Roisman GI (2019) The secure base script concept: An overview. Curr Opin Psychol 25:162-166

93. Wolfram S (1986) Theory and applications of cellular automata. World Sci

94. Wu Z, Lin T, Li M (2019) Automated detection of children at risk of chinese handwriting difficulties using handwriting process information: An exploratory study. IEICE Trans Inf Syst 102:147-155

95. Vafashoar R, Morshedlou H, Rezvanian A, Meybodi MR Cellular Learning Automata: Theory and Applications

96. Vaivre-Douret L, Lopez C, Dutruel A, Vaivre S (2021) Phenotyping features in the genesis of prescriptural gestures in children to assess handwriting developmental levels. Sci Rep 11:1-13

97. Van Der Linden R, Lopes R, Bidarra R (2014) Procedural generation of dungeons. IEEE Trans Comput Intell AI Games 6:78-89. https://doi.org/10.1109/TCIAIG.2013.2290371

98. Viner RM, Russell SJ, Croker H, et al (2020) School closure and management practices during coronavirus outbreaks including COVID-19: a rapid systematic review. Lancet Child Adolesc Heal

99. Zhang Z, Li Z, Han M et al (2021) An augmented reality-based multimedia environment for experimental education. Multimed Tools Appl 80:575-590

100. Zomarshidi H (2001) Iranian Architecture: Building with traditional materials (in Farsi)

Publisher's note Springer Nature remains neutral with regard to jurisdictional claims in published maps and institutional affiliations. 